\title{
Informes
}

\section{Homenaje a Carlos Javier Echarri Cánovas}

\section{Tribute to Carlos Javier Echarri Cánovas}

\section{Resumen}

El Colegio de México rindió un homenaje póstumo al destacado demógrafo Carlos Javier Echarri Cánovas, quien fuera distinguido profesor-investigador del Centro de Estudios Demográficos y Urbanos (CEDUA) de esa institución, así como también secretario general del Consejo Nacional de Población. En el acto participaron Silvia Elena Giorguli, presidenta de El Colegio de México (Colmex); Olga Sánchez Cordero, secretaria de Gobernación; Alejandro Encinas, subsecretario de Derechos Humanos, Población y Migración de la Secretaría de Gobernación; Brígida García, Profesora Emérita de El Colegio de México; Manuel Ordorica Mellado, profesorinvestigador del CEDUA; Patricia Noemí Vargas Becerra, presidenta de la Sociedad Mexicana de Demografia (Somede) y profesora-investigadora de la Universidad de Guadalajara; Edith Pacheco Gómez, profesora-investigadora del CEDUA; Julieta Pérez Amador, profesora-investigadora del CEDUA; Karla Yukiko López Magaña, egresada de la maestría en Demografía del Colmex; Manuel Echarri Cotler, estudiante de la licenciatura en Ciencias Políticas de la UNAM; María del Puy Echarri Cánovas, responsable de Prevención de Accidentes en la Secretaría de Salud de Guanajuato, en Moroleón; y Guadalupe Cánovas Fonseca, madre de Carlos Echarri. El acto fue moderado por Jaime Sobrino, director del CEDUA. A continuación, reproducimos las palabras de los oradores en el orden de su presentación.

\begin{abstract}
El Colegio de México paid a posthumous tribute to acclaimed demographer Carlos Javier Echarri Cánovas, formerly a distinguished research fellow at the Center for Demographic and Urban Studies (CEDUA) and Secretary General of the National Population Council. Participants at the event included Silvia Elena Giorguli, president of El Colegio de México (Colmex); Olga Sánchez Cordero, Secretary of the Interior; Alejandro Encinas, Undersecretary of Human Rights, Population and Migration of the Ministry of the Interior; Brigida Garcia, Professor Emerita at El Colegio de México; Manuel Ordorica Mellado, CEDUA research fellow; Patricia Noemi Vargas Becerra, president of the Mexican Society of Demography (Somede) and research fellow at the University of Guadalajara; Edith Pacheco Gómez, research
\end{abstract}


fellow at CEDUA; Julieta Pérez Amador, CEDUA research fellow; Karla Yukiko López Magaña, a Colmex Master's Degree Program in Demography graduate; Manuel Echarri Cotler, a UNAM Political Science Bachelor's Degree Program student; Maria del Puy Echarri Cánovas, Director of Accident Prevention at the Ministry of Health of Guanajuato, in Moroleón; and Guadalupe Cánovas Fonseca, mother of Carlos Echarri. The event was moderated by Jaime Sobrino, director of CEDUA. The speakers'words are given below in order of presentation.

\section{Palabras de Silvia Elena Giorguli ${ }^{1}$}

\section{Carlos Echarri, reconocido profesor-investigador de esta institución, demógrafo creativo y comprometido con sus temas, colega y amigo}

En esta tarde los recibo en mi calidad de presidenta de esta institución, El Colegio de México. Les agradezco su presencia y que nos acompañen en esta ceremonia que tiene a la vez un carácter íntimo, de reconocimiento al colega y amigo, e institucional, de reconocimiento a un gran demógrafo.

Saludo con mucho cariño a Helena, Santiago y Manuel, a la madre de Carlos, Guadalupe Cánovas, y a toda la familia Echarri, Cánovas y Cotler. Saludo también a quienes fueron sus colaboradores y jefes, entre ellos y especialmente, a Olga Sánchez Cordero y a Alejandro Encinas; a los compañeros del Conapo que nos acompañan; a sus alumnos, desde los más recientes hasta los de las primeras generaciones a quienes impartió clase; a sus colegas (y también míos) de El Colegio, del gremio de demógrafos y de otras instituciones; a sus amigos y a todos los que nos acompañan y que vienen hoy con nosotros a recordarlo.

Me costó mucho trabajo preparar las palabras que les dirijo ahora porque no encontraba la forma lo suficientemente elocuente de expresar, de manera simultánea:

- la pérdida que, para muchos, representa la ausencia de Carlos, desde diversos ámbitos, y, al mismo tiempo,

- reconocer sus contribuciones y todo lo que nos deja, desde la parte más humana y personal, hasta la del ámbito profesional, en lo relacionado a la política de población, en la academia y en la investigación demográfica.

1 Presidenta de El Colegio de México, A.C. 
Hay muchas formas de recordar a nuestro querido Carlos y muchas razones para reconocerlo hoy y en el futuro. Sé que quienes me acompañan en esta mesa lo harán desde diversos ángulos y con mayor detalle. En lo personal, me cuesta trabajo hablar de la trayectoria del colega sin caer en la tentación de las referencias anecdóticas.

Quisiera enfocar mi participación para reconocerle a Carlos sus contribuciones en esta institución, no sólo en el CEDUA, sino también en el Sindicato de Profesores-Investigadores (Siprin), en el Comité del Plan de Pensiones, en el Programa de Salud Reproductiva y Sociedad, en el Consejo Académico y en las discusiones colegiadas.

Me hubiera gustado expresarle directamente mi reconocimiento a:

- la agudeza de sus comentarios,

- lo apasionado en sus compromisos, entre ellos, la agenda de género en El Colegio,

- lo creativo de sus visiones para abrir nuevos campos, como el de la violencia y el feminicidio en México, o el del impacto de las estructuras familiares en la salud de los hijos (desde su tesis de doctorado),

- su generosidad en tiempo y para compartir ideas, sistematizar información (como cuando se tomó la tarea de organizar todas las bases de datos sociodemográficas de INEGI que teníamos en formato SPPS, y nos las compartió a colegas y estudiantes),

- su empeño para revisar y discutir metodologías antiguas y nuevas,

- su capacidad para vincular la agenda de investigación con la pública, para combinar el trabajo académico sin sacrificar el diálogo con los tomadores de decisiones, generadores de información, organismos internacionales y sociedad civil. Es un ejemplo de que se puede combinar y vincular el trabajo académico con la agenda pública en nuestro quehacer como demógrafos.

Pero, sobre todo, me hubiera gustado agradecerle su estilo franco y honesto de decir las cosas en un marco de gran respeto y compromiso institucional, y su sincera apertura -sin esperar nada a cambio, como me comentó alguien del personal administrativo de El Colegio.

No voy a enumerar todas las comunicaciones, expresiones de solidaridad y de tristeza que recibí de colegas en México, en América Latina y en el mundo. Pero son, a final de cuentas, la expresión de todo lo que caracterizaba a Carlos en México y fuera del país.

A su familia y a los colegas que nos acompañan, quiero decirles que lo de hoy no es un cierre. Tenemos dos trabajos de Carlos ya en etapa de pu- 
blicación, que aparecerán entre este año y principios del próximo. Los menciono porque son ejemplo del trabajo del colega, de la pertinencia de las discusiones que articulaba y de su compromiso académico.

- Está en proceso editorial un libro en coedición Colmex-ONU Mujeres sobre la agenda 2030, los avances y retos en los ODS y género en México. Fue un trabajo colectivo que nos reunió a muchos. Yo tuve la fortuna de participar con el capítulo de educación. Teníamos y mantenemos el compromiso de terminar el proceso de revisión y edición del libro. Le agradezco a Julieta Pérez Amador, quien nos apoyará en esta etapa final del trabajo.

- Y también está en prensa el libro colectivo Dinámica demográfica de México en el siglo XXI, que coeditamos Luis Jaime Sobrino y yo, y en el que Carlos escribió el capítulo sobre "Violencia y feminicidio". Esta obra colectiva -son dos tomos- estará dedicada tanto a Alejandro Mina como a Carlos Echarri. Con ello, reconocemos y honramos el trabajo de ambos en el CEDUA.

Y como estamos recordando hoy a Carlos, me voy a tomar la libertad de leer un fragmento del párrafo final de su escrito, en cuanto a la necesidad de enfrentar el núcleo duro de la violencia feminicida en México. A partir de su investigación, reconoce que: "resulta indispensable modificar los patrones culturales que hacen que los hombres consideren a las mujeres como objetos de su propiedad, de los que pueden disponer e incluso aniquilar y desechar, para poder efectivamente erradicar la violencia contra las mujeres". Después de la lectura de su conclusión final, no necesito decir más sobre su compromiso y sus aportes desde la investigación para entender la violencia contra las mujeres.

Me había propuesto al principio no comentar alguna anécdota (por hacerle justicia a las muchas que podría contar), pero quisiera terminar con una personal -aunque también de carácter institucional- que refleja mucho del carácter de Carlos.

Desde que asumí, primero la Dirección del Centro hace diez años, y después la Presidencia, Carlos me señaló reiterada e insistentemente que el código postal de El Colegio estaba mal. Al principio no le entendía. ¿Qué código? ¿Cómo sabe alguien que el código postal de un lugar está mal? No sé si sería un poco de la influencia de Helena en su espíritu de ver las cosas desde la dimensión geográfica o espacial... pero, finalmente, después de muchos años -al menos una década - el tiempo le dio la razón y el código postal de El Colegio se corrigió. Esto fue apenas un par de años atrás. 
Ese era nuestro querido Carlos, insistente, observador de aspectos que los otros omitíamos, persistente y atinado; pero, sobre todo desde la perspectiva de El Colegio, alguien con un gran compromiso con la institución que lo formó, que lo apoyó en la continuación de su formación, en la cual desarrolló toda su carrera académica y para la que guardaba un profundo agradecimiento y un gran respeto.

Quiero cerrar agradeciendo la presencia de quienes nos acompañan en esta mesa, a Luis Jaime y al CEDUA por la organización de este acto académico, y especialmente a Helena, Santiago y Manuel, a su madre, Guadalupe, por su generosidad para compartir con nosotros durante todos estos años un pedacito del esposo, del padre y del hijo.

\section{Palabras de Olga Sánchez Cordero²}

Con gran cariño y remembranza estoy con ustedes en este prestigiado recinto académico, alma mater de algunos de los más importantes personajes de la vida pública e intelectual de México. Agradezco la invitación de la doctora Silvia Giorguli y su hospitalidad.

Quiero saludar con mucho respeto a los familiares de nuestro querido Carlos Javier Echarri Cánovas, que se encuentran con nosotros, así como a todos sus amigos y compañeros en el Centro de Estudios Demográficos, Urbanos y Ambientales, en El Colegio de México, en el Consejo Nacional de Población y en la Secretaría de Gobernación.

Como todos saben, nuestro querido Carlos estudió Actuaría en la UNAM, la maestría en Demografía en El Colegio de México y el doctorado en el Instituto de Demografía en la Universidad de Lovaina, Bélgica.

$\mathrm{Su}$ trayectoria académica fue muy extensa: trabajó en el Centro de Estudios Demográficos, Urbanos y Ambientales, donde fue coordinador académico de la maestría en Demografía y del doctorado en Estudios de Población; colaboró en El Colegio de Frontera Norte y en El Colegio de Sonora. $\mathrm{Su}$ destacada trayectoria le permitió alcanzar el nivel III del Sistema Nacional de Investigadores.

Carlos Echarri fue miembro de distintas organizaciones internacionales relacionadas con los estudios de población, fungió como presidente de la Sociedad Mexicana de Demografía y presidió el Consejo Consultivo Ciudadano para la Política de Población. También fue miembro del Comité Científico Asesor del Diagnóstico Nacional sobre Violencia contra las Mujeres,

\footnotetext{
2 Secretaria de Gobernación.
} 
vocal del Comité de Prevención del Consejo Nacional para la Prevención y Control del Sida, así como vocal académico y coordinador del Comité de Monitoreo y Evaluación del Conasida.

Otro de los grandes logros alcanzados por el doctor Echarri fue encabezar la Secretaría General del Consejo Nacional de Población, que es, como ustedes saben, la institución dedicada a la planeación demográfica del país para incluir a la población en los programas de desarrollo económico y social.

En el Conapo tuvimos el privilegio de contar con la amplia experiencia y conocimientos de nuestro querido Carlos, en donde compartió con nosotros su visión sobre los temas prioritarios de la dinámica demográfica, así como su profundo interés hacia el reconocimiento y respeto de los derechos humanos, los cuales formarán parte de su legado.

Sé que para Carlos lo más importante fue y es siempre su familia; durante nuestras conversaciones encontramos una gran coincidencia en que más allá de los logros profesionales y académicos, la familia es el núcleo más valioso para todos los seres humanos, y es lo que nos identifica y nos hace vivir con plenitud. Platicábamos sobre el gran amor y respeto que tuvo para Helena Cotler, su compañera de vida, con quien compartió sus logros y estuvo casado por 25 años. Sus ojos se iluminaban cuando hablábamos de sus hermosos hijos Santiago y Manuel, quienes deben sentirse muy orgullosos de ser hijos de Carlos Javier Echarri Cánovas.

\section{Palabras de Alejandro Encinas ${ }^{3}$}

En primer lugar, agradezco a Silvia Giorguli la invitación para poder participar en este muy merecido homenaje a nuestro querido compañero Carlos Echarri y tener la oportunidad de compartir este evento con Helena, con su familia, con su señora madre, con sus amigas y con sus amigos.

Evidentemente, este es un homenaje que entraña una profunda tristeza, pero estoy seguro de que a Carlos Echarri le gustaría mejor ver una sonrisa, porque si algo tengo siempre presente de Carlos es, además de su muy buen sentido del humor, una actitud muy positiva ante la vida. Podemos hablar mucho de Carlos, de su experiencia profesional, de su claridad mental, de su sentido crítico, de su intachable trayectoria personal y académica, así como de su profundo amor por la vida. Pero de lo que más podemos hablar, lo que destaca de la personalidad de Carlos, sin lugar a dudas fue su profunda calidad humana, ya que siempre estuvo preocupado por lo demás. Esa

\footnotetext{
3 Subsecretario de Derechos Humanos, Población y Migración, Secretaría de Gobernación.
} 
actitud sin lugar a dudas la llevó siempre en su desempeño académico, profesional y también en el servicio público, donde el país y el gobierno del presidente López Obrador tuvimos el privilegio de tenerlo al frente de la política de población del gobierno mexicano.

Como ya señalaban tanto Silvia como Olga, Carlos puso en el centro las preocupaciones y los temas fundamentales que estamos enfrentando como retos enormes en nuestro país: el embarazo infantil, los derechos sexuales y reproductivos de los hombres y las mujeres en México, el problema de la población desplazada y la visión de una política poblacional que debe recuperar fundamentalmente los derechos humanos de las personas.

Yo tuve la oportunidad de participar durante el proceso de transición en la definición de quienes iban a ocupar distintas responsabilidades dentro del gobierno federal. Tengo muy presente una reunión que tuvimos, junto con Gabriela Rodríguez, con Ari, allá en la colonia Condesa, en donde estábamos vislumbrando quién podría ayudarnos en la conducción del Consejo Nacional de Población. La verdad es que no fue muy difícil, menos aún después de haber pasado el examen de oposición al que fui sometido aquí en El Colegio de México, con todos los demógrafos, para pedirle a Carlos que nos acompañara al frente del Consejo Nacional de Población.

Lo cierto es que Carlos Echarri llegó al Consejo con una visión innovadora, con muchas iniciativas y con un equipo de trabajo, al que le pido que continúe ayudándonos a impulsar las ideas e iniciativas que Carlos promovió. Ese equipo se integró con muchos de sus alumnos, con la gente que a lo largo de su carrera profesional fue formando y que puede ser la simiente de una nueva generación que le dé continuidad a las muy importantes aportaciones de Carlos, no solamente en las políticas poblacionales o demográficas, sino en muchas políticas públicas que estábamos impulsando y que lo seguiremos haciendo en el Consejo Nacional de Población.

Y por eso, creo que a Carlos tenemos que verlo con una visión de futuro, porque sus aportaciones siguen vigentes y tenemos el compromiso de cristalizarlas. Les voy a poner un ejemplo: el día de hoy les traigo el anteproyecto de la Ley General para Prevenir, Atender y Reparar Integralmente el Desplazamiento Forzado Interno en nuestro país, que fue elaborada con Carlos junto con los compañeros de la Secretaría de Gobierno, con Jorge Wheatle, del Registro Nacional de Población, y con Rocío González, de la Unidad de Política Migratoria. Queremos denominarle Ley Echarri porque es uno de sus más importantes legados en este periodo -muy corto, de siete meses- al frente del Consejo Nacional de Población; queremos presentarla como una iniciativa el próximo periodo de sesiones del Congreso de la Unión. Todavía está en la fase de anteproyecto porque, como Carlos también quería, 
debe ser objeto de un amplio proceso de consulta, por lo cual se la dejó a Silvia Giorguli, para que El Colegio de México, los compañeros de la Sociedad Mexicana de Demografía y todos los interesados, nos ayuden a que este proyecto se cristalice, para que las inspiraciones, los esfuerzos y los legados de Carlos, continúen formando parte de las políticas y de la vida pública de nuestro país.

\section{Palabras de Brígida García ${ }^{4}$}

Me honra dirigirles unas palabras en este homenaje a nuestro compañero Carlos Echarri, a quien conocí como un joven estudiante en El Colegio de México, y de quién pude seguir sus pasos como doctorante en la Universidad de Lovaina la Nueva, y luego como colega en múltiples actividades en El Colegio de México y en la Sociedad Mexicana de Demografía.

Algunos de quienes me precedieron en este homenaje, y sin duda los que me seguirán, harán referencia a la diversidad de actividades que Carlos desarrollaba en los medios académicos, gubernamentales, de la sociedad civil y en los organismos internacionales. Fue sin duda muy intensa su dedicación profesional dentro de nuestra institución y su participación en comisiones y comités evaluadores de políticas públicas específicas en los temas de su especialidad. En este marco, pensé que una perspectiva apropiada para mi intervención serían sus contribuciones académicas y docentes. En poco tiempo resulta difícil hacer justicia en esta dirección, pero espero llamar su atención sobre algunas contribuciones que considero de interés particular.

Una primera fue la tesis de doctorado de Carlos, la cual fue subsecuentemente publicada en forma de su primer libro. Éste constituye una aportación original y poco frecuente en nuestro medio. En el contexto sociodemográfico, pero especialmente en países asiáticos, se prestaba mucha atención a finales del siglo pasado a las relaciones entre el estatus de la mujer, la fecundidad y la salud infantil; sin embargo, en México no había suficiente interés en estos temas.

Con este trasfondo, Carlos abrazó esta investigación sobre estructura familiar y salud de los niños con particular apasionamiento, lo cual era una característica conocida de su personalidad. Recuerdo muy vivamente que en ese entonces me invitaron a formar parte de una comisión en la Organización Mundial de la Salud en Ginebra, que duró varios años, y Carlos se esforzaba en viajar de Bélgica a Suiza para discutir con los que seguíamos su tesis

\footnotetext{
${ }^{4}$ Profesora Emérita de El Colegio de México, A.C.
} 
sobre sus avances y tropiezos. El eje central del estudio consistía en demostrar que en el análisis de la fecundidad y de los cuidados a la salud, el estatus de la madre en el hogar era un factor con efecto significativo. Había que confirmar que el pertenecer a la tercera generación en un hogar constituía una desventaja para los niños, pero que los mecanismos y hechos eran diferentes si la madre era hija o nuera del jefe del hogar. Más que una discriminación de los niños sobre la base del sexo, como es el caso en otras sociedades, el examen de los determinantes de los cuidados a la salud nos hace pensar en la posibilidad de que tal discriminación se base en el linaje, en la existencia o no de lazos de sangre. Carlos se preguntaba: ¿serán mejor atendidos los descendientes por parte de la madre que aquellos por parte del padre? Y a los ojos de los abuelos, ¿se otorgará mayor valor o se considerará más fácilmente que forman parte de la familia los hijos de sus hijas mujeres que los de sus hijos varones? El análisis multivariado que llevó a cabo confirmó muchas de estas aseveraciones.

Para interpretar más ampliamente sus resultados, Carlos razonaba también de la siguiente manera. El proceso de atención médica se inicia con el reconocimiento de las necesidades en cuidados a la salud y continúa con la decisión de buscar tales cuidados. Es posible que en lo que respecta a la toma de decisiones para llevar el niño al médico, o pedir consejo en la farmacia, aquellas mujeres con una posición de dependencia en sus hogares, como las nueras, enfrenten no sólo las opiniones de sus maridos, sino también las de sus suegras. Se trata sin duda alguna de razonamientos importantes y que no habían recibido suficiente atención, sobre todo teniendo en cuenta que este estudio fue llevado a cabo en la década de los noventa del siglo pasado.

Una segunda contribución académica de Carlos Echarri, que no deberíamos soslayar, se refiere a sus aportes en torno a la desigualdad social y el comportamiento sociodemográfico. Es útil recordar que uno de los rasgos centrales de la sociodemografía latinoamericana es la consideración de la desigualdad social existente en nuestros países en términos de clases, sectores o estratos sociales, así como de otros ejes como serían el género y la condición étnica. En términos metodológico-técnicos, inicialmente la noción de clase o sector social fue introducida mediante información referida al jefe del hogar. Sin embargo, éramos conscientes de las limitaciones que esta decisión entrañaba, pues así se atribuían las características del jefe a toda su unidad doméstica, además de los problemas que ya representaba la identificación del jefe o jefa del hogar. Fue una contribución muy relevante de Carlos Echarri el diseño muy creativo de un índice de estratificación social que tomó en cuenta la información concerniente a todos los miembros de la unidad doméstica referente a la vivienda, la escolaridad y la generación de 
ingresos. Este indicador ha sido construido para una diversidad muy amplia de encuestas e introducido en muchas bases de datos. Se trata de una contribución teórico-metodológica de impacto y que ha suscitado airadas controversias, como suele ocurrir con los buenos aportes.

Una tercera línea de estudio y de acción pública de Carlos muy trascendente se refiere a los feminicidios. Llevó a cabo un esfuerzo continuo por medirlos y así hacerlos visibles, junto con otras investigadoras, mediante el análisis de las defunciones femeninas con presunción de homicidio. Los reportes que se elaboraron en distintas ocasiones con base en las estadísticas vitales son sumamente relevantes desde el ángulo de la política pública, pero también desde lo que podríamos llamar un acercamiento demográfico al feminicidio.

En estas publicaciones se ha explotado de manera muy minuciosa la información contenida en las estadísticas vitales de mortalidad a partir de los certificados de defunción, y así se ha conocido su tendencia en el tiempo desde 1985, así como su distribución en los diferentes estados y municipios del país. Resulta muy valioso consultarlos en estos momentos en los que, lamentablemente, la violencia de género ha cobrado especial dramatismo en el país. De esta manera, se estimula el análisis de las causas y los efectos de este flagelo, lo cual resulta indispensable para respaldar las políticas y los recursos necesarios para frenarlo.

Las reflexiones anteriores se refieren principalmente a la investigación sociodemográfica, pero mi participación quedaría muy inconclusa si no compartiera con ustedes mi experiencia como coprofesora con Carlos Echarri. Impartimos varias veces, también en compañía de otras investigadoras en nuestra institución, cursos sobre familias y trabajo en nuestros posgrados. Diseñamos estos cursos de modo que varias generaciones participáramos en la enseñanza y discutiéramos los diferentes puntos de vista. Contrario a lo que a veces necesariamente ocurre, por los múltiples compromisos de cada quién, me sorprendía, especialmente la última vez que impartimos un curso, que Carlos demostraba su compromiso estando presente siempre, aunque no fuera el maestro expositor. Yo percibía que los alumnos disfrutaban de constatar nuestras distintas perspectivas, de argumentar en torno a los ejemplos que Carlos aportaba como conocedor de varios idiomas y culturas.

En la elaboración de los programas, Carlos insistía en que complementáramos la perspectiva sociodemográfica con la antropológica, la historiográfica y la jurídica. Conocía bien los códigos civiles y penales de la Federación y de los diferentes estados de la República, y le complacía mostrarnos a todos la importancia de las diferencias entre ellos. En el terreno de los estudios poblacionales hacía mucho hincapié en las diversas maneras en que 
la familia o el hogar-unidad doméstica habían sido concebidos y captados en distintas encuestas y censos, y cultivó la subespecialidad sobre demografía de la familia a lo largo de toda su carrera profesional.

Pudiera relatarles muchas otras aportaciones académicas y anécdotas profesionales para celebrar la fecunda vida de Carlos de la manera que creo que le hubiera gustado hacerlo. Sin embargo, es tiempo de concluir y sólo me resta extender un cariñoso abrazo a su esposa, a sus hijos y a toda su familia.

\section{Palabras de Manuel Ordorica Mellado 5}

En primer lugar, quiero agradecer a Silvia Giorguli y a Luis Jaime Sobrino la oportunidad de hablar en este homenaje sobre mi amigo Carlos Echarri.

El fallecimiento de Carlos me ha entristecido mucho. Su muerte contra natura fue ayudando a otros, consistente con su vida. Siempre fue un gran amigo, muy querido, generoso y honesto. Carlos Echarri fue mi alumno en Análisis Demográfico III, en la generación 1985-1987. Les daba yo el curso de Poblaciones Estables. Carlos era un estudiante aplicado, tenía una buena formación matemática que le venía de la carrera de actuario en la UNAM, pero además poseía una gran inquietud social, que plasmaba en sus análisis.

Su tesis de maestría fue una evaluación de la calidad de la información de la Encuesta Nacional sobre Fecundidad y Salud de 1987. Me dio mucho gusto que siguiera mis pasos en la evaluación de encuestas. Yo había hecho la valoración de la Encuesta Mexicana de Fecundidad de 1976. Creo que son las dos únicas encuestas que se han evaluado en forma sistemática. Carlos entendía muy bien que los datos se deben revisar con lupa antes de empezar a analizarlos y a decir cosas sobre ellos. En cambio, la calidad del dato hoy ya no es un campo de interés entre los demógrafos.

Siempre estuvo interesado en lo que pasaba con los grupos más vulnerables, analizando los temas sociodemográficos que más estaban afectando a la sociedad: los altos índices de feminicidios, los masculinicidios, los infanticidios (son los invisibles), la salud reproductiva, los jóvenes, la mortalidad materna, entre otros temas. El hecho de que mueren por homicidio nueve hombres por cada mujer era de mucho interés para él y también lo es para mí. Es una catástrofe humana, los homicidios le están restando casi cinco años a la esperanza de vida al nacer.

${ }^{5}$ Profesor investigador del Centro de Estudios Demográficos, Urbanos y Ambientales de El Colegio de México. 
Recuerdo que después de haber hecho su doctorado en Lovaina, Bélgica, estuvo durante algún tiempo en el Programa de Salud Reproductiva de El Colegio de México (Colmex), el cual luego coordinó.

En el Colmex, Carlos fue coordinador de la maestría en Demografía y del doctorado en Población, así como integrante de la Junta de Profesores de la maestría de Género, Procesos Políticos y Transformaciones Culturales; fue presidente de la Sociedad Mexicana de Demografía (Somede); miembro del Comité Científico Asesor del Diagnóstico Nacional sobre Violencia contra las Mujeres; y fue integrante del jurado del Premio Nacional de Demografía, 2000 y 2014, entre otros de sus reconocimientos y logros. Había llegado al nivel más alto en el SNI. Sólo le faltó ser director del Centro de Estudios Demográficos, Urbanos y Ambientales (CEDUA). Una vez que terminara su periodo en el Conapo, seguramente regresaría a El Colegio de México para seguir su trayectoria académica.

A Carlos lo recuerdo con mucho cariño porque siempre estaba atento a que se cumplieran los principios y estaba listo a resolver problemas. Se molestaba mucho cuando algún profesor o profesora se metía en sentido contrario en el estacionamiento del Colmex. Era una persona estricta, quería que se cumplieran los principios; creo que a veces era incomprendido porque en nuestro país no se habla tan directo. Quería resolver ese profundo y añejo problema de muchos mexicanos y mexicanas de no cumplir reglas.

Nuestros orígenes estaban muy cerca, la ciudad de Echarri-Aranaz, ubicada en Navarra, y Ordorika-Auzoa, que pertenece al país vasco, están a sólo 63 kilómetros de distancia en línea recta, como a una hora en carro. Platicábamos de que teníamos un espíritu aguerrido. Podíamos discutir fuerte y enojarnos por cuestiones académicas, pero al rato todo se olvidaba y luego seguíamos siendo tan amigos como siempre. No había rencores. Esa fue una de sus grandes virtudes, su muy buen corazón.

Me da mucha pena que no llegue a ver realizados los grandes logros de la política de población de la Cuarta Transformación, con la que estamos muchos de nosotros y él, desde luego; pronto tendremos seguramente en todas partes del país la legalización del aborto, casi cero embarazo adolescente, cero muertes maternas, una esperanza de vida de 80 años o más (al periodo de 2000 a 2018 lo llamaremos los casi dos decenios perdidos por lo que respecta al nulo aumento en la esperanza de vida al nacer); esperamos cero muertes por homicidios, una tasa casi cero de mortalidad infantil y cero muertes por diabetes, así como una migración interna e internacional regulada.

El presidente de la República, Andrés Manuel López Obrador, tiene en su mente y en la acción una política demográfica regional dirigida al sur y 
sureste, sólo falta incorporarle la demografía, es decir, la gente. Esos son los objetivos y metas que se deberán cumplir poco a poco en la política de población. A ello siempre aspiramos Carlos y yo. Comentábamos de una nueva ley de población ya prácticamente lista, aunque eso no impide funcionar con la existente para elevar la calidad de vida y regular los componentes demográficos. Hablábamos del problema financiero y social del siglo XXI: el envejecimiento poblacional, ligado a la pobreza, y cómo enfrentarlo no con palabras, sino con una solución social, actuarial y demográfica.

Por cierto, Carlos y yo decíamos que esperábamos un censo con cobertura de casi $100 \%$. En su memoria yo estaré muy atento al censo de 2020 para que sea muy bueno. Ese era uno de sus propósitos, ver un censo perfecto o casi perfecto. Ojalá eso ocurra.

Pasando a otra cosa, en una ocasión me habló por teléfono y me dijo que el INEGI iba a realizar estimaciones y proyecciones de población, y que él no estaba de acuerdo. Le dije que coincidía con él. Le comenté que las proyecciones de población las debe hacer el Conapo porque ellas deben indicar el país al que aspiramos, qué futuro queremos. No es suficiente tener la proyección tendencial, aunque sí es un referente de comparación.

Recuerdo que una ocasión estaba saliendo yo de El Colegio de México como a las seis de la tarde y caía una lluvia con granizo. Se hizo un río de agua y piedras que bajaban de la montaña por la avenida Camino al Ajusco. El camino se hizo muy peligroso pues no se veía. Yo estaba en el carro oyendo las noticias de la radio. Pensé, esa voz la conozco: era Carlos Echarri informando en una estación de radio que estaba al aire, que había unas piedras enormes en el pavimento de Camino al Ajusco por la tremenda lluvia. Él no se quedaba en las palabras, iba a la acción, siempre buscando informar a la gente. Cuando había algún problema entre conductores, discutiendo acaloradamente, se metía a separarlos para que las palabras no pasaran a mayores. Carlos rompía con la forma de ser de muchos mexicanos. Siempre buscaba resolver problemas. Fue un gran promotor del programa de prevención y atención de riesgos en El Colegio de México. Lo recuerdo con su chaleco anaranjado de protección civil dirigiendo la salida del personal de la institución en los simulacros.

Carlos tenía muchas publicaciones entre libros, artículos y capítulos de libros sobre la violencia, los feminicidios, la estructura familiar, la salud materno-infantil y la salud reproductiva, entre otros temas. Se encontraba en el apogeo en su vida como académico y recientemente como funcionario del Conapo.

Quiero darle mi más sentido pésame a Helena, su esposa, a sus hijos, Santiago y Manuel, a su mamá y a todos sus familiares. Quiero decirles a 
sus hijos que tuvieron un padre ejemplar, que lo llevaremos en nuestro corazón y en nuestra mente. Una persona que siempre estuvo atenta para ayudar a los demás. Carlos para mí no ha muerto, lo llevo en mi mente como ejemplo de generosidad y honestidad. Algo que haré en mis programas de los cursos que imparto es poner en la bibliografía varios de sus trabajos, será la forma que tendré para recordarlo y homenajearlo continuamente, y para que las generaciones futuras de demógrafos sepan quién fue Carlos Echarri.

\section{Palabras de Patricia Noemí Vargas Becerra ${ }^{6}$}

La historia de la Sociedad Mexicana de Demografía está marcada por las contribuciones académicas y las trayectorias vitales de los demógrafos y estudiosos de la población que la formamos. Honrar la labor y la memoria de cada uno está en el corazón de nuestra comunidad. En este homenaje quiero destacar el incansable trabajo que Carlos Echarri, distinguido demógrafo, colega y amigo, entregó a nuestra Somede.

En 1968, siendo estudiante de la maestría en Demografía de El Colegio de México, participó por primera vez como asistente en la III Reunión Nacional de Investigación Demográfica en México. El año 1989 marca su ingreso como miembro de esta sociedad científica. Sí, treinta años de contribuir a la permanencia y el cambio de la Somede. Carlos fue presidente del Consejo Directivo 2015-2017, vicepresidente en el periodo 2013-2015, secretario de la Coordinación Técnica entre 2004-2006, y miembro del Comité Científico.

La agenda académica y personal de Carlos siempre estuvo marcada por sus compromisos con la Somede: colaboró de diversas formas, compartiendo sus conocimientos en ponencias y conferencias en doce reuniones nacionales y distintos foros convocados por la Sociedad. Además, fue acucioso comentarista y organizador de mesas y sesiones temáticas en estos mismos eventos. Su preocupación por las inequidades sociales marcó las aportaciones de Carlos desde sus trabajos sobre estratificación sociodemográfica y salud materno-infantil hasta sus investigaciones sobre familia, género y discriminación, salud sexual y reproductiva, violencia y feminicidio. Siendo vicepresidente de la Somede colaboró intensamente con Carla Pederzini para la realización de la XII Reunión Nacional titulada "A 40 años: ¿la familia

${ }^{6}$ Presidenta de la Sociedad Mexicana de Demografía (Somede) y profesora-investigadora de la Universidad de Guadalajara, México. 
pequeña vive mejor?". Como presidente de nuestra sociedad organizó la XIII Reunión Nacional de Investigación Demográfica en México, cuyo tema central fue dinámicas de población y desigualdad, con el objetivo de reflexionar y entender cómo las desigualdades sociales permiten definir distintos ritmos y procesos de la dinámica sociodemográfica en los diversos grupos de población.

Como buen demógrafo, siempre promovió la inclusión de temas relacionados con la producción de información demográfica en los eventos de la Somede, participando en el análisis y evaluación de los censos, estadísticas vitales y encuestas, datos fundamentales para la conciliación demográfica y las proyecciones de población. Una de sus últimas preocupaciones estaba relacionada con el Censo de Población y Vivienda que se realizará en nuestro país en 2020, tema que mantendremos vigente en la agenda de nuestra sociedad.

Para Carlos, las reuniones nacionales también eran una oportunidad para el reencuentro y la convivencia académica y fraterna, con sus colegas, sus compañeros y amigos. Con su eterna sonrisa, su gran sello de distinción, siempre estaba pendiente de los detalles personales de quienes tuvimos la oportunidad de conocerle. Carlos, la sociedad no dejará de ser ese espacio de encuentros y reencuentros que tú ayudaste a forjar.

Soy portadora también de las voces de América Latina que se unen aquí y ahora en este homenaje.

La Asociación Latinoamericana de Población reconoce a Carlos como miembro distinguido por ser impulsor y fundador de esta sociedad. La comunidad de estudios de la población de América Latina reconoció su liderazgo eligiéndolo para formar parte del primer Consejo Directivo, de 2004 a 2006. Siempre atento a los problemas demográficos de la región, participó en los ocho congresos realizados por la ALAP en diferentes países de América Latina. Por su trayectoria académica y conocimiento fue portador de la voz de esta sociedad científica en diversos foros.

El Centro Latinoamericano de Demografía (Celade) reconoce el destacado papel de Carlos Echarri como representante de México en la Conferencia Regional sobre Población y Desarrollo y desea transmitir a la comunidad de demógrafos y estudiosos de la población de México su más profunda solidaridad y cercanía en este homenaje.

La Asociación Peruana de Demografía y Población también hace patente su reconocimiento a Carlos por los lazos de estrecha amistad con sus asociados, especialmente con sus compañeros de estudio, por las enseñanzas compartidas en cada visita que realizó a Perú -su segunda patria, como siempre lo manifestó-, recordándolo por su carisma, liderazgo, ejemplo de 
calidad humana y como un profesional comprometido con los temas sociales y demógrafos.

La Asociación de Estudios de Población de la Argentina se une también a este homenaje reconociendo el recorrido, la historia y la huella de Carlos Echarri, que trascendió fronteras nacionales por su generosidad que no entendió de límites político-jurisdiccionales. Y por ser un activo impulsor de los estudios de población en América Latina. Carlos Grushka, presidente de esta asociación, destaca la preocupación de Carlos por los derechos humanos, en particular en lo referido a las desigualdades de género, que lo llevó a trascender los entornos académicos para tender puentes con la gestión, aportando sus conocimientos y saberes en los espacios de decisión: una virtuosa combinación de investigación y acción puesta al servicio y en beneficio de la sociedad.

Por su parte, la naciente Asociación Chilena de Población (Achidepo) reconoce a Carlos como ejemplo por su incansable trabajo en la difusión y posicionamiento de los temas de población y de los derechos humanos en la agenda social y política de América Latina, destacando sus convicciones sobre la lucha por un mundo donde el respeto de los derechos humanos sea la regla. Por ello, proponen que se establezca un reconocimiento, premio y/o distinción que lleve por nombre "Doctor Carlos Echarri", y que se otorgue a aquellos miembros de cualquier asociación de la región que hayan tenido una labor destacada o un logro significativo en la defensa de los derechos humanos, particularmente del derecho de las mujeres a una vida sin violencia, y en la reducción de las desigualdades de género, propósito que Carlos tuvo entre sus prioridades.

La Asociación Brasileña de Estudios de Población solicitó a Ana María Nogales Vasconcelos, compañera de Carlos durante sus estudios de doctorado, se expresara a nombre de la ABEP:

Recuerdo al niño que fui a rescatar en una noche fría y lluviosa, típica de Louvainla-Neuve, y que acababa de llegar de la Ciudad de México para hacer su doctorado. Este primer contacto me reveló su personalidad cuando me relató la ruta que eligió para el viaje de la Ciudad de México a Bruselas. Había elegido un vuelo con escala en Islandia. ¿Es eso cierto? ¡Sí, Islandia! ¿Quién pensaría en algo así? Ese era Carlos. Siempre aprovechó las oportunidades para nuevas miradas, nuevas formas, nuevas experiencias de vida. Carlos no meditaba los esfuerzos personales para contribuir a una causa justa y necesaria. En este tributo, quiero reconocer un poco de su sonrisa, de su determinación, de su alegría y de su amor por los demás. 
Helena, Santiago, Manuel: la Sociedad Mexicana de Demografía les agradece el habernos permitido compartir grandes momentos de la vida de Carlos, siempre estaremos con ustedes.

Carlos: tu inesperada partida aún nos tiene conmovidos y tu ausencia deja un vacío que permanecerá latente, porque aquí nadie olvida, porque somos eso... memoria.

\section{Palabras de Edith Pacheco Gómez ${ }^{7}$}

Al conocer la triste noticia de Carlos, Rosario Cárdenas, Silvia Giorguli y yo escribimos unas palabras buscando compartir nuestra profunda tristeza, pero especialmente nuestro reconocimiento, admiración y cariño por él. Trataré de leer algunos pasajes de este escrito. Pero también quisiera compartir con ustedes algunos recuerdos de Carlos, que de cierta manera me ayudan a mitigar el dolor de su partida.

Como muchos de ustedes saben, cuando Carlos solamente tenía 21 años de edad ingresó a la maestría en Demografía aquí en El Colegio de México. La generación 1985-1987 tuvo el privilegio de vivir con él muchos momentos felices. Rosario y yo quisiéramos compartirles dos anécdotas de ese tiempo: una referida al uso de la tinta y su mala letra, al punto que en una ocasión un profesor le pidió que fuera a su cubículo a leerle e interpretarle sus respuestas; estamos convencidas que esa letra está en la base de lo tecnologizado de su andar, ya que siempre estaba muchos pasos delante de nosotros. Otra anécdota tiene que ver con el papel central que jugó en nuestra fiesta de graduación: el carácter ciudadano de Carlos le permitió conseguirnos la Casa Popular de La Magdalena Contreras, en avenida Luis Cabrera, para nuestro festejo. Fuera de las normas convencionales, bailamos a morir y llenos de placer comimos unas ricas quesadillas elaboradas por las mujeres de la colonia. Los de la generación nunca olvidaremos ese momento.

Muchos años después, el carácter ciudadano de Carlos hizo que lograra algo que para mucho de nosotros parecía impensable. Un día se topó con que se había cerrado la calle Llanura, en el Pedregal, vía alterna al Periférico que corre desde Insurgentes a la avenida Paseo de Pedregal. Carlos no desistió, día con día hablaba para lograr que todas las personas pudiéramos transitar libremente por ese espacio. Cuando finalmente lo logró, muchos nos llenamos de admiración y nos hizo aprender que el ser ciudadano signi-

${ }^{7}$ Profesora-investigadora del Centro de Estudios Demográficos, Urbanos y Ambientales de El Colegio de México. 
fica tener responsabilidades y compromisos, y que al ejercer nuestros derechos podemos hacer cambiar la realidad.

Ahora bien, la trayectoria laboral de nuestro querido Carlos es muy amplia. Al terminar la maestría trabajó en la Dirección General de Planificación Familiar de la Secretaría de Salud Pública. Inició su trayectoria académica al regresar del doctorado en Lovaina y hasta el 30 de noviembre pasado fue profesor-investigador de esta institución, en la que ocupó en dos ocasiones el cargo de coordinador académico de la Maestría en Demografía, y también coordinó el Doctorado en Estudios de Población. En sus distintas funciones en El Colegio de México fue reconocido como una persona brillante.

Beatriz Estrella y Alejandra Franco -ambas fueron sus secretarias- escribieron unas palabras para nosotros:

El año pasado a tres coordinaciones del CEDUA les tocó la renovación del PNPC de Conacyt. En ese arduo trabajo, que duró varios meses y reuniones semanales, Carlos, por su personalidad, compromiso y trabajo, se convirtió en el líder del equipo. Con Carlos, siempre un paso delante de nosotras, teníamos la certidumbre de que el CEDUA obtendría exitosamente la renovación de sus programas.

Estoy segura que tanto Ana, Jimena, Natalia, Lupita y Alejandra, integrantes del equipo, comparten esta opinión.

Además de un trabajo intenso en El Colegio de México, Carlos participó de múltiples maneras en otras instituciones nacionales e internacionales. Sólo por mencionar algunas en el ámbito nacional: El Colegio de la Frontera Norte, el Centro Regional de Investigaciones Multidisciplinarias (CRIM) de la Universidad Nacional Autónoma de México (UNAM) y El Colegio de Sonora. En el ámbito internacional, en años recientes colaboró con ONUMujeres en el marco de su año sabático.

Su participación en distintas instancias internacionales, gubernamentales y de la sociedad civil fue amplia. Fue miembro de la International Union for the Scientiific Study of Population (IUSSP), de la Asociación Latinoamericana de Población (ALAP) y de la Population Association of America (PAA) y, entre 2015 y 2017 fungió como presidente de la Sociedad Mexicana de Demografía (Somede).

Fue presidente del Consejo Consultivo Ciudadano para la Política de Población, miembro del Comité Científico Asesor del Diagnóstico Nacional sobre Violencia contra las Mujeres CRIM-UNAM/Conavim, vocal del Comité de Prevención del Consejo Nacional para la Prevención y Control del 
Sida (Conasida), vocal académico y coordinador del Comité de Monitoreo y Evaluación del Conasida.

La combinación de un muy buen académico, a la vez que una persona preocupada por el respeto de los derechos humanos de las personas, lo llevó a participar en distintas batallas, las cuales siempre estuvieron sostenidas por un análisis de la realidad con amplios fundamentos. En particular, la búsqueda por incidir en la reducción de las desigualdades de género era una de sus preocupaciones más apremiantes, aspecto que lo llevó en los últimos tiempos al tema de los feminicidios, una de las problemáticas más alarmantes en nuestro país.

Al inicio de este escrito decíamos que su trayectoria de vida ha sido vasta, su sonrisa permanente era un indicador de una existencia enriquecida en distintos planos. Uno de ellos fue la vida compartida con su esposa Helena Cotler y sus hijos Santiago y Manuel. Al hablar de ellos se le llenaban los ojos de orgullo, presumía a su esposa como una investigadora brillante y una excelente compañera de vida; a sus hijos, como uno de los regalos más preciados de su existencia. Algunos tuvimos la suerte de convivir con ellos y formar una amplia familia que perdurará a la ausencia de Carlos.

Carlos también fue amigo de muchísimas personas. Sería difícil en este espacio hacer un recuento de ellas, sólo baste decir que él consideraba esta dimensión de su vida de un gran valor y nos lo hacía sentir, por eso muchos estamos devastados por su pérdida. Un botón de prueba de la importancia de este plano de su vida era el papel que jugaba cuando viajábamos a congresos. Primero que nada, era un ejemplo a seguir en cuanto a las posibilidades de intercambio académico en esos espacios; sabía perfectamente cuáles eran los temas de punta y debatía con gran pasión, lo que nos asombraba y enorgullecía completamente. Pero también lograba compartir generosamente con sus amigos y amigas su amplia cultura, el placer por la vida y el valor sustantivo que los pequeños momentos implican para la amistad.

Nosotras, colegas, compañeras de batallas y especialmente amigas de Carlos, no podemos dejar de pensar en el gran vacío que deja. Estamos ciertas que una persona como él es absolutamente irremplazable, pero, como dicen sus alumnos, perdurará en nuestros corazones y ha dejado semillas que seguramente honrarán su existencia.

Carlos Echarri será recordado por su sentido del humor, su amplio conocimiento de los temas demográficos, su solidaridad con diversas causas sociales y su generosa contribución en la formación de alumnos estudiosos de la población. 


\section{Palabras de Julieta Pérez Amador ${ }^{8}$}

Quiero empezar por agradecer a los organizadores por la invitación, es para mí un honor compartir con ustedes estos momentos.

Mi relación con Carlos está claramente definida en cuatro etapas, y de esa forma quiero compartírselas.

Primera etapa. Nos conocimos cuando yo era becaria de investigación de Gustavo Cabrera, y uno podría pensar que el becario del director del Centro tendría un escritorio donde trabajar, pero no era así: los becarios compartíamos los equipos del salón de cómputo. Y fue precisamente Carlos quien, a pesar de no beneficiarse de nuestro trabajo, gestionó que se nos asignara un espacio, al que en su momento llamamos "la caballeriza", y que compartimos por un tiempo Adriana, Hiram y yo. Carlos venía todas las mañanas a saludar y a invitarnos un café en la sala de profesores, desafiando las relaciones jerárquicas de la institución.

Segunda etapa. Y esta tiene un título "No creas que porque somos amigos voy a tener preferencia". Y efectivamente, mi peor nota en la maestría en Demografía me la dio Carlos. Para mí siempre fue claro que él sería mi director de tesis, era algo completamente lógico en mi cabeza, pero no necesariamente para él. Cuando llegó el momento de elegir director, le planteé lo que quería hacer; me dijo que muy bien, pero que tenía que cambiar de tema a algo de salud reproductiva, a lo que respondí: "Carlos, es mi tesis no la tuya". Él sólo me miró. Me fui muy enojada, no sé por cuantos días me duró el enojo, pero volví diciéndole que esta era su oportunidad de ampliar horizontes y estudiar nuevos temas. La verdad no me acuerdo qué tanto me costó convencerlo, pero al final dijo que sí. Y me hizo trabajar y trabajar y trabajar. Tuve que aprender a usar CSPro y a programar en SPSS; lo peor de todo es que las computadoras no eran tan buenas, entonces sólo podía usar su computadora, súper rápida, por dos horas diarias mientras él iba a comer, entonces me tocaba ocuparme y dedicarme.

Ya con los datos listos, que obviamente tomó mucho tiempo, llegó el momento en que teníamos que usar análisis de historia de eventos; yo le dije que eso no se enseñaba en la maestría, a lo que respondió tranquilamente: "No hay problema, aprendemos". Fuimos a la biblioteca, revisó los libros, tomó el Cox \& Oakes, se lo quedó, y me dio el Yamaguchi, diciendo "Leamos, en una semana vemos la syntaxis en SPSS". Yo quedé en shock. Me acuerdo que fui con mi amigo Juan Manuel, compañero de la maestría, y le dije, "no

${ }^{8}$ Profesora-investigadora del Centro de Estudios Demográficos, Urbanos y Ambientales de El Colegio de México, A.C. 
inventes, Carlos cree que puedo hacer esto como si fuera él". Y sí, ese era el mensaje del momento y el que marcó de ahí en adelante nuestra relación: él siempre me vio como su par, con las mismas capacidades, incluyendo la capacidad de autoaprendizaje.

La dirección de tesis terminó, y la tercera etapa, de colaboración, inició: trabajamos en un par de proyectos y comenzamos a escribir juntos. A pesar de la distancia geográfica de esta etapa, siempre mantuvimos contacto. Escribimos un artículo sobre las transiciones de la juventud a la edad adulta, que resulta ser, hasta la fecha, el trabajo más citado tanto para mí como para él. Cada año aumentaba el conteo y bromeábamos con desaparecerlo para que ya nos citaran individualmente. Pero al mismo tiempo, como buenos demógrafos, celebrábamos los bloques quinquenales y esperábamos con ansia la llegada de la cita 100, como cuando en un partido de baloncesto un equipo anota 100 puntos y la casa se desborda. Ya aquí me entrelacé con la cuarta etapa.

Nuestra última etapa fue la de colegas, la prueba más fehaciente de la igualdad sustantiva. La mayoría de las veces coincidíamos en rumbos y opiniones, pero algunas veces no. Nos tocó discutir, ya se imaginarán el choque titánico de caracteres, pero siempre el diálogo estaba abierto, así como la libertad de diferir. Nos tocó enojarnos, desenojarnos y pedirnos disculpas. Esta etapa de colegas la puedo resumir con tres palabras: respeto, igualdad y apoyo. Siempre respeto, siempre igualdad, siempre apoyo.

Más que nada, Carlos siempre fue mi amigo, él escuchó las historias de mi curso de vida, las historias buenas, las historias no tan buenas, desde la juventud a la adultez. En mis etapas personales y profesionales difíciles, la dualidad de nuestra relación me confortaba: por un lado, era la amistad y el trato de pares, por el otro era de nuevo ese mentor, avalado por la experiencia ganada por los años y el curso de vida más avanzado, que siempre ofrecía un buen consejo.

Además de guardar todo en lo más profundo de mi corazón, la manera de honrar lo que Carlos me dio es la transmisión intergeneracional. Mis alumnos y yo estamos en distintas etapas del curso de vida. Si hago ver a cada uno de ellos que en el peor de los casos somos igualmente capaces, y en el mejor de los casos ellos son más capaces que yo, lo estaré honrando. Yo siempre voy a pedir y esperar lo mejor de ellos porque él siempre pidió lo mejor de mí. 


\section{Palabras de Karla Yukiko López Magaña9}

Durante mi paso por El Colegio de México tuve la oportunidad de conocer al profesor Carlos Echarri en distintas de sus facetas: como coordinador de la Maestría en Demografía, como profesor, como director de tesis y como persona. Me extenderé en platicar mi experiencia respecto a éstas dos últimas circunstancias.

Como coordinador de la Maestría en Demografía siempre se mostró abierto a debatir las quejas y sugerencias de nuestra promoción (2016-2018). Por ejemplo, después del sismo de septiembre de 2017, le solicitamos por correo que nos ayudara a aplazar las evaluaciones de mitad de semestre ya que algunos de mis compañeras y compañeros se encontraban en labores de apoyo a los damnificados, y la falta de concentración en los estudios podría afectar nuestro desempeño. Él no sólo accedió a hablar con los profesores para que nos dieran un plazo extra para la entrega de trabajos, sino que nos citó a una reunión para escucharnos y pudiéramos externar nuestras preocupaciones y sentimientos respecto al evento que nos conmovió de diferentes maneras.

A la par, tuve la fortuna de conocerlo como profesor, pues estuvo a cargo del curso Introducción a los Estudios de Población y del de Nupcialidad. En ambos propiciaba el debate sobre los temas más relevantes en la agenda demográfica y, al menos en mí, provocaba una serie de interrogantes que me llevaba a casa para reflexionar. Fue después de realizar un trabajo final para su clase de Nupcialidad que empezó mi interés sobre el tema de violencia de género, en particular la dirigida a las mujeres y niñas, y cómo afecta el curso de vida de éstas.

Por lo tanto, tras una meditación profunda sobre quién podría ser mi director de tesis, decidí que no había una opción más óptima que el profesor Echarri, quien además de tener un conocimiento vasto en el estudio de las transiciones a la vida adulta, también mostraba sensibilidad y preocupación por temas como la violencia hacia las mujeres y la defensa de sus derechos. Así pues, me dispuse a presentarle mi tema de investigación y pedirle que dirigiera mi de tesis. Desde el momento en que llegué a su oficina, él me escuchó con mucha atención y se mostró interesado; cuando le pedí que fuera mi director de tesis, me dijo: "Con todo gusto". Enseguida me compartió una carpeta de Dropbox (la cual contenía más de 100 artículos, libros, informes, etc. sobre mi tema), me prestó dos libros y luego me dijo que a partir de ese momento nos veríamos todos los lunes para revisar avances. Al

9 Egresada de la maestría en Demografía de El Colegio de México, A.C. 
principio me sentí bastante abrumada; sin embargo, también reconocí el esfuerzo que él hacía para atenderme desde la semana inmediata a nuestra primera reunión.

Cuando me invitaron a hacer una intervención en este homenaje, anduve buscando dentro de mis memorias una anécdota ocurrida durante el proceso de tesis para compartir con ustedes, que fuera la que más representara la excelente calidad humana y profesionalismo del doctor Echarri. Al hacer esta remembranza, encontré que todas eran únicas y especiales. No obstante, en todas me recuerdo entrando en su oficina (la puerta siempre abierta), él ocupado en un millón de cosas y dando respuesta a correos y solicitudes que le llegaban a diario, pero siempre me recibió con una sonrisa y con tiempo para escuchar mis dudas y brindarme las herramientas para resolverlas.

Lo que más valoro son los retos a los que me enfrentó. Había veces que me dejaba investigar temas, procedimientos y calcular o construir variables que yo no tenía ni idea de por dónde empezar; él me daba el indicio, más no la solución. A la siguiente semana, cuando regresaba a su oficina muy satisfecha de haber resuelto el enigma, me daba cuenta de que no era nada nuevo para el profesor Echarri; es más, él sabía más de lo que yo había podido investigar. Pero en el camino de buscar la solución había aprendido mucho, y por ello estoy muy agradecida con él.

La última vez que lo vi fue en el Coloquio de Salud y Género, donde presenté los resultados de mi tesis. En ese momento pude platicar con él sobre dónde había conseguido trabajo, y le regresé los libros que me había prestado, entre otros asuntos. Antes de despedirme, me preguntó si ya me había inscrito al Premio Carmen Miró; le respondí que todavía no, que pensaba hacerlo muy pronto (la verdad todavía no me sentía segura de participar). Él me sugirió que no dejara de hacerlo, que no dejara pasar esa gran oportunidad. Así pues, seguí su sabio consejo y meses más tarde ganamos el primer lugar. Al recibir la noticia, inmediatamente pensé en él. Enseguida le escribí un correo para contarle la buena nueva y agradecerle por todo: tiempo, esfuerzo, compromiso, correcciones, comentarios, paciencia y todo lo que implica ser director de tesis. Lamentablemente no tuve la oportunidad de agradecerle en persona. Espero que él supiera del reconocimiento, gratitud y gran cariño que le tengo.

Como persona me tocó conocer a un hombre que escuchaba no sólo mis inquietudes y dificultades sobre la tesis, sino también personales. Varias veces tuve que solicitarle que nos viéramos en otro horario o día porque se presentaban situaciones con mis hijos; amablemente me decía que no me preocupara y me agendaba otra cita. Asimismo, le gustaba platicar sobre sus

Estudios Demográficos y Urbanos, vol. 35, núm. 1 (103), enero-abril, 2020, pp. 243-268 
experiencias en conferencias, reuniones, seminarios. Incluso una vez se tomó la molestia de tomarle una foto a una chica que se llamaba igual que yo para mostrármela, ya que le pareció curioso que existiera otra estudiante de demografía llamada Yukiko.

En fin, el doctor Echarri representa para mí una de las personas más significativas en mi curso de vida, y en verdad esperaba que estuviera muchos años más con nosotros. Me quedé con muchas consultas por hacerle, inquietudes por expresarle y cosas por platicar. El profesor Echarri es un modelo para seguir, ya que mezclaba academia con compromiso social, pues no sólo buscaba el porqué, sino también una solución. Sin duda su presencia es muy extrañada, su legado jamás será olvidado y seguiremos andando por el camino que él nos trazó.

\section{Palabras de Manuel Echarri Cotler ${ }^{10}$}

Primero que nada, muchas gracias por las participaciones de la mesa, son muy importantes para nosotros. Gracias a El Colegio de México -que al final de cuentas era la segunda casa de mi papá- por organizar este bonito, pero a la vez triste evento.

Mi papá, Carlos, el que todos ustedes conocieron, era una persona que no dejaba indiferente a nadie donde quiera que él estuviese, como han relatado acá. No ha habido una batalla que él dejara pasar, desde un acalorado debate en un foro internacional hasta parar a un conductor en el periférico para decirle que sus luces estaban descompuestas. De principio a fin él tuvo una fuerte convicción por ayudar a quien lo necesitara, y esa solidaridad y calidad humana es un aprendizaje de lo que realmente todos acá tenemos que ser parte. Pero mi papá también era una persona con una curiosidad inagotable y con unas ganas muy fuertes de compartir al mundo su conocimiento. Yo, como su hijo, tuve la suerte de poder tener incontables discusiones con él, realmente de una manera muy horizontal, en las que cambiábamos e intercambiamos puntos de vista de su trabajo, de los problemas sociales, del actuar del gobierno, de lo que veíamos en mis clases, de muchas cosas.

Como se ha mencionado aquí, él fue un gran académico, quien desde su área de estudio buscó aportar al país soluciones a algunos de sus problemas más importantes. En el poco tiempo que pudo estar al frente del Conapo, estoy seguro de que fue un gran servidor público, con una ética profesional

${ }^{10}$ Estudiante de la licenciatura en Ciencias Políticas de la Universidad Nacional Autónoma de México. 
impecable. Respecto a esas dos cosas, ustedes acá lo saben mejor que yo. Pero lo que yo les puedo decir es que también fue un gran padre, mejor de lo que mi hermano y yo jamás podríamos haber pedido: uno que siempre, siempre, estaba presente. Para mí realmente era una enciclopedia viviente, ante cualquier duda que podría tener yo, cualquier problema que necesitara solución, él estaba ahí para ayudarme. Por eso es realmente duro perderlo. También era una persona con la que, como todos ustedes saben, se podían compartir gustos, y se podían compartir preocupaciones. Él realmente le daba importancia a lo que pensaban las demás personas.

Gran parte de lo que yo soy, gran parte de lo que yo quiero ser, es por él, por mi papá, por Carlos Echarri. Yo sé que las personas no mueren hasta que son olvidadas. Tengo la certeza de que todos acá nos vamos a llevar algo de los incontables aprendizajes que ha dejado en nosotros, pues a pesar de todo, aunque todo haya cambiado tan abruptamente de un día para otro, mi cariño y mi amor hacia él nunca van a cambiar.

\section{Palabras de María del Puy Echarri Cánovas ${ }^{11}$}

Agradezco a todos los que organizaron este homenaje a Carlos Echarri. Soy su hermana y aunque se oye raro, pues soy mayor que él, siempre lo he admirado mucho. Cuando era niño prefería estar leyendo, investigando, antes que estar jugando. Siempre fue muy inteligente, muy estudioso, desde pequeño. Eso también se lo debemos a mi mamá porque ella nunca tuvo que decirnos ¡siéntate a hacer la tarea! o ¡si no estudian...! o ¡si no cumplen...! Era algo que se daba por hecho en la casa, había que salir bien en la escuela. ¡Gracias mamá!

Carlos destacaba desde que era estudiante. Conocemos a muchos de sus compañeros porque cuando hizo la maestría aquí, iban a la casa y estudiaban o comían ahí, o hacían fiestas. Carlos tenía muchos compañeros extranjeros, por lo tanto, en la casa nos enseñaron a brindarles la misma atención que a la familia.

Posteriormente, él se fue a hacer el doctorado a Lovaina y yo ya no vivía en la Ciudad de México, estaba en Moroleón; en ese entonces mi mamá se puso mal, le dio un infarto y tuve que regresar a México. Le hablaba a mi hermano, y escuchaba cómo se ponía él; me preocupaba porque estaba mucho más lejos que yo. Gracias a Dios, mi mamá salió bien. Moroleón.

${ }^{11}$ Responsable de Prevención de Accidentes en la Secretaría de Salud de Guanajuato, en 
A mi hermano también le tengo que agradecer mucho todo el apoyo que le dio a mi hija desde que se vino a estudiar aquí la carrera (posteriormente ella se quedó aquí).

Los temas que más le importaban a Carlos, casualmente son los que también me interesan. Yo soy médico y trabajo también con éstos, no al nivel que lo hizo Carlos, pero son temas que en mi ámbito los veo diariamente: el feminicidio, el embarazo en adolescentes y la situación de los migrantes.

Hoy aquí escuché algo que de hecho cambió un poco mi futuro. Yo estaba dedicada a la prevención de accidentes, pero desde el día que Carlos falleció, decidí dejar ese programa a un lado; no quería saber nada de él porque me afectaba mucho. Si me dedico a eso, ¿cómo pudo haber fallecido Carlos en un accidente? Pero hoy que escuché que él también estaba en la prevención de riesgos, con su chaleco naranja (el mío es rojo y azul porque estoy a cargo), creo que le debo a él continuar con ese programa a nivel estatal. Yo había decidido dejarlo a un lado, pero, así como sus compañeros y mucha gente dice que tiene que seguir su legado, creo que también tengo que continuar por la memoria de mi hermano.

Elena y niños: los quiero mucho y siempre vamos a estar con ustedes.

\section{Palabras de Guadalupe Cánovas Fonseca ${ }^{12}$}

Cuando Carlos tenía cuatro años, yo me fui de directora a un centro de desarrollo comunitario en Jiquilpan, Michoacán. Ese centro lo instauró don Lázaro Cárdenas. Parte de los que soy como persona se lo debo a doña Amalia, a sus hermanas y a él mismo. Estoy muy orgullosa de que mis cinco hijos siempre han tenido compromiso social, siempre. Cuando estaba ahí de directora, un día fue a visitarnos don Lázaro y Carlos andaba corriendo por ahí con cuatro años; se acercó y don Lázaro le puso la mano en la cabeza y me preguntó: “¿De quién es hijo?”. Dije: “¡Mío!”. Entonces me comentó: "Cuídame mucho a este niño porque tú no sabes lo que tienes en él”. Fue la visión de don Lázaro, cuando Carlos apenas tenía cuatro años.

12 Madre de Carlos Echarri Cánovas. 